\title{
Política educacional e formação continuada dos professores da educação infantil de
}

\section{Fortaleza: dilemas, percursos e perspectivas}

\author{
Educational policy and continuing education of teachers of early childhood education in Fortaleza: \\ dilemmas, paths and perspectives \\ Política educativa y formación continua del profesorado de educación infantil en fortaleza: dilemas,
} rutas y perspectivas

\section{Resumo}

A política educacional se enquadra no tipo de política majoritária, em que o governo tem responsabilidade e competência em oferecer a todos os brasileiros a educação básica, com acesso, permanência e qualidade, e faz parte dos direitos constitucionais do cidadão brasileiro no artigo $5^{\circ}$ da Constituição Federal de 1988. A educação pública tem legislação própria, que determina, diretrizes, funções e seu funcionamento: a LDB n. ${ }^{\circ}$ 9.394/1996, conjuntamente com o PNE, Lei n. ${ }^{\circ}$ 13.005/2014, estabelece metas, estratégias e ações para a educação brasileira pelo período determinado de uma década. A formação de professor é uma política pública que busca responder pela qualificação do ensino público e vencer os desafios que permeiam os contextos escolares, fato que compromete a aprendizagem dos alunos, além de promover valorização profissional ao docente. O artigo expressa a correspondência dos objetivos estabelecidos no Programa de Formação Continuada de Professor da Educação Infantil, realizado pela rede pública municipal de Fortaleza no período de 2017 a 2018, investigando os resultados obtidos segundo as narrativas dos sujeitos pesquisados. O programa de formação continuada em 2017 teve por objetivo a reelaboração da proposta pedagógica das instituições públicas municipais de Fortaleza. Em 2018, o objetivo elegeu o fortalecimento do currículo da educação infantil, com a pedagogia de projetos, para promover os direitos de aprendizagem das crianças estabelecidos na BNCC (Brasil, 2017). A pesquisa foi realizada em unidades escolares do Distrito 3, no período de setembro a novembro de 2020. O público-alvo foram professores, coordenadores pedagógicos e técnicos-formadores com atuação na etapa da educação infantil, segmento pré-escola. A literatura pesquisada utilizou de documentos pertinentes a educação pública das esferas: nacional, estadual e municipal. Segundo as narrativas dos sujeitos, foi possível concluir que, em 2017, o objetivo proposto foi alcançado em sua plenitude, mas em 2018, não foi possível lograr de pleno êxito, em virtude dos fatores que envolvem as concepções e os conhecimentos no âmbito do currículo da educação infantil.

Palavras-chave: Política pública; Formação continuada; Educação infantil; Proposta pedagógica; Pedagogia de projetos.

\footnotetext{
Abstract

Educational policy fits into the type of majority policy, in which the government has the responsibility and competence to offer all Brazilians basic education, with access, permanence and quality, and is part of the constitutional rights of the Brazilian citizen in article 5 of the Constitution. Federal of 1988. Public education has its own legislation, which determines guidelines, functions and their functioning: LDB No. 9,394/1996, together with the PNE, Law No. Brazilian education for a determined period of one decade. Teacher training is a public policy that seeks to respond to the qualification of public education and overcome the challenges that permeate school contexts, a fact that compromises student learning, in addition to promoting professional appreciation for teachers. The article expresses the correspondence of the objectives established in the Program for Continuing Education of Teachers of Early Childhood Education, carried out by the municipal public network of Fortaleza from 2017 to 2018, investigating the results obtained according to the narratives of the researched subjects. The continuing education program in 2017 aimed to re-elaborate the pedagogical proposal
} 
of municipal public institutions in Fortaleza. In 2018, the objective was to strengthen the early childhood education curriculum, with the pedagogy of projects, to promote the learning rights of children established in the BNCC (Brazil, 2017). The research was carried out in school units in District 3, from September to November 2020. The target audience were teachers, pedagogical coordinators and technical-trainers working in the early childhood education stage, pre-school segment. The researched literature used documents relevant to public education in the following spheres: national, state and municipal. According to the narratives of the subjects, it was possible to conclude that, in 2017, the proposed objective was reached in its entirety, but in 2018, it was not possible to achieve full success, due to the factors that involve the conceptions and knowledge within the scope of the curriculum. of early childhood education.

Keywords: Public policy; Continuing training; Child education; Pedagogical proposal; Project pedagogy.

\section{Resumen}

La política educativa se inscribe en el tipo de política mayoritaria, en la que el gobierno tiene la responsabilidad y competencia de ofrecer a todos los brasileños educación básica, con acceso, permanencia y calidad, y forma parte de los derechos constitucionales del ciudadano brasileño en el artículo 5 de la Constitución Federal de 1988. La educación pública tiene su propia legislación, que determina directrices, funciones y su funcionamiento: LDB $\mathrm{N}^{\circ}$ 9.394/1996, junto con el PNE, Ley $\mathrm{N}^{\circ}$ de Educación Brasileña por un período determinado de una década. La formación docente es una política pública que busca responder a la cualificación de la educación pública y superar los desafíos que permean los contextos escolares, hecho que compromete el aprendizaje de los estudiantes, además de promover la valorización profesional de los docentes. El artículo expresa la correspondencia de los objetivos establecidos en el Programa de Formación Continuada de Profesores de Educación Infantil, realizado por la red pública municipal de Fortaleza de 2017 a 2018, investigando los resultados obtenidos según las narrativas de los sujetos investigados. El programa de educación continua en 2017 tuvo como objetivo reelaborar la propuesta pedagógica de las instituciones públicas municipales de Fortaleza. En 2018, el objetivo fue fortalecer el currículo de educación inicial, con la pedagogía de proyectos, para promover los derechos de aprendizaje de los niños establecidos en el BNCC (Brasil, 2017). La investigación se llevó a cabo en unidades escolares del Distrito 3, de septiembre a noviembre de 2020. El público objetivo fueron docentes, coordinadores pedagógicos y técnicos-formadores que actúan en la etapa de educación inicial, segmento preescolar. La literatura investigada utilizó documentos relevantes para la educación pública en los siguientes ámbitos: nacional, estatal y municipal. De acuerdo con las narrativas de los sujetos, fue posible concluir que, en 2017, el objetivo propuesto fue alcanzado en su totalidad, pero en 2018, no fue posible alcanzar el éxito total, debido a los factores que involucran las concepciones y conocimientos. en el ámbito del currículo de educación infantil.

Palabras clave: Política pública; formación continua; Educación Infantil; Propuesta pedagógica; Proyecto de pedagogía.

\section{Introdução}

A educação brasileira vem atravessando momentos de constantes mudanças, a política educacional congrega força de atuação política a partir da Constituição Federal de 1988, no seu artigo 205, que determina: “A educação, direito de todos e dever do Estado e da família, será promovida e incentivada com a colaboração da sociedade, visando ao pleno desenvolvimento da pessoa, seu preparo para o exercício da cidadania e sua qualificação para o trabalho". Definição clara e objetiva dos fins da educação básica, instituindo a quem cabe tamanha responsabilidade.

Com o propósito de qualificar o ensino público, a Lei n. ${ }^{\circ}$ 12.056/2009 (Brasil, 2009a) altera o artigo 62 da LDB n. ${ }^{\circ}$ 9.394/1996 (Brasil, 1996) e estabelece em seu parágrafo primeiro a responsabilidade de todas as esferas públicas com a política de formação de professores, compõe a política educacional e representa um fator relevante na qualificação da ação docente, tendo como consequência direta responder aos problemas da educação brasileira, no tocante ao processo de ensinoaprendizagem da educação básica, realizado pela rede pública (Brasil, 2009a). A valorização do magistério perpassa pela formação do professor, ancorada como política pública, para fortalecer a identidade do profissional em educação e melhorar a qualidade do trabalho docente, em função da eficácia e efetividade a favor da formação integral de bebês e crianças da educação infantil.

A política pública de formação continuada para docentes na rede municipal de ensino de Fortaleza faz parte dos programas, planos e projetos dos governos nas esferas federal, estadual e municipal, segundo estabelece a LDB nº $9.394 / 96$ e o 
PNE/2014, no qual as Metas 15 e 16 determinam como responsabilidade do poder público a oferta de formação inicial e continuada aos professores da educação básica para qualificar a prática pedagógica do professor e assegurar acesso, permanência e qualidade ao ensino público, fundamentos essenciais da política educacional brasileira (Brasil, 1996; 2014).

Diante do exposto, o presente artigo pretende fazer uma análise crítica do programa de formação continuada da rede pública municipal de Fortaleza, na etapa da educação infantil nos anos de 2017 e 2018, buscando verificar se os objetivos propostos foram alcançados segundo as narrativas dos sujeitos pesquisados. No ano de 2017, a rede municipal elegeu como objetivo principal da formação a reelaboração da proposta pedagógica das unidades escolares. Em 2018, a temática formativa deu ênfase à pedagogia de projetos, com o propósito de fortalecer o currículo da educação infantil na garantia dos direitos de aprendizagem (participar, conviver, brincar, explorar, expressar e conhecer-se) das crianças de 1 a 5 anos. Os anos consecutivos buscaram potencializar, de forma didática e significativa, a ação pedagógica dos professores.

A política de formação de professores se compromete com a formação integral do aluno e com a valorização dos profissionais da educação básica, em uma articulação permanente entre teoria e prática ancorada no tripé ensino, pesquisa e extensão. O percurso formativo corrobora para reduzir as “desigualdades sociais, regionais e locais” (BRASIL, 2019, p. 3).

O Programa de Formação Continuada de Professores da rede pública de Fortaleza expressa, em sua essência, as

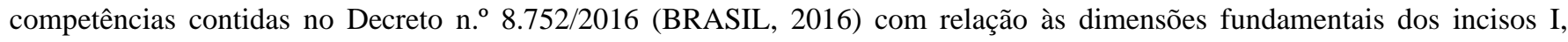
conhecimento profissional, II, prática profissional, e III, engajamento profissional, que abordam o compromisso do professor com o seu próprio desenvolvimento profissional, sendo algo que precisa ser bem mais enfatizado (BRASIL, 2019, p. 2). Nesse sentido, Imbernón (2011) destaca que:

[...] a formação assume um papel que transcende o ensino que pretende uma mera atualização científica, pedagógica e didática e se transforma na possibilidade de criar espaços de participação, reflexão e formação para que as pessoas aprendam e se adaptem para poder conviver com a mudança e a incerteza (Imbernón, 2011).

O autor faz uma análise da suposta pretensão da formação continuada e acrescenta outras atribuições necessárias à formação docente, apresentando as condições básicas para a convivência e interação do profissional na sociedade do século XXI. O professor precisa ter capacidade reflexiva sobre sua prática, ter autonomia pedagógica, participar das discussões para elaboração do Projeto Político Pedagógico (PPP) da escola e, por fim, promover debates sobre o papel da escola na formação do novo ser humano, para enfrentar e conviver nesse novo contexto social de um mundo diverso e globalizado.

\section{Metodologia}

O objeto da pesquisa consiste em um estudo qualitativo, com análise crítica sobre os impactos da formação continuada na prática docente e no processo de desenvolvimento e aprendizagem das crianças de 0 a 5 anos. Como metodologia, foram utilizados dois instrumentais distintos: questionários coletados de forma eletrônica (e-mails) e análise documental de leis, resoluções e publicações referentes ao tema proposto. A opção por essas ferramentas possibilitou acesso aos profissionais da educação infantil, permitindo uma maior fidedignidade à pesquisa, que ocorreu nos meses de setembro a novembro de 2020, considerando o contexto histórico e social de pandemia da Covid-19, fato que impossibilitou a realização da pesquisa de forma presencial.

Importante salientar que, a pesquisa foi aprovada pelo Comitê de Ética da Universidade Estadual do Ceará (UECE), e validada pela Secretaria Municipal de Educação (SME), com autorização para realização em escolas e centros de educação infantil da Rede Municipal de Fortaleza. O público alvo da pesquisa contou com a participação efetiva de coordenadores pedagógicos, professores e técnicos formadores que no período de 2017 e 2018 estavam em pleno exercício de suas funções. 
Os dados foram tabulados, seguindo uma análise qualitativa, a partir das narrativas dos sujeitos, que responderam a um questionário específico, proposto para cada segmento de profissionais da educação básica, com recorte aos professores que atuaram na educação infantil (pré-escola) no período delimitado pela pesquisa.

\section{Resultados e Discussão}

A pesquisa buscou compreender se o Programa do Curso de Formação Continuada de Professor da rede pública municipal de Fortaleza, na etapa da educação infantil, no período de 2017 e 2018, conseguiu alcançar os objetivos expressos, segundo as narrativas dos sujeitos pesquisados. Refletindo sobre os dados da pesquisa, a partir das narrativas dos sujeitos, foi possível constatar que o programa de 2017, que teve por objetivo, a construção da proposta pedagógica das unidades escolares da rede municipal de Fortaleza, conseguiu lograr de pleno êxito. O programa de formação continuada de 2018, teve o propósito de fortalecer o currículo da educação infantil, inserindo o trabalho com a pedagogia de projetos, para garantir os direitos de aprendizagem (participar, conviver, brincar, explorar, expressar e conhecer-se) das crianças de 0 a 5 anos, propostos pela Base Nacional Comum Curricular (BNCC/2017). Segundo as narrativas expressas pelos sujeitos pesquisados, o objetivo do programa de formação de 2018, não conseguiu alcançar êxito, devido as questões relacionadas com as concepções pedagógicas e práticas docentes, ainda arraigadas a pedagogia tradicional.

A formação continuada avança e recua, constituindo um processo dialógico de relação entre o saber teórico e a prática, articulação necessária que promove a identidade profissional ao professor e fortalece sua qualificação permanente. A escola, como lócus do trabalho pedagógico, também não conseguiu acompanhar os avanços e as transformações da nova era, continua sendo organizada sob os parâmetros do pensamento e ideias do século passado, no que tange ao seu funcionamento, currículo, tempos, espaços e atuação dos professores, fatores que constituem desafios a serem vencidos pela nova era do conhecimento e pelos avanços da tecnologia.

Imbernón (2009) defende a formação permanente do professor nas instituições de ensino, em um processo de “ação-reflexão-ação", em que os planos de formação devem partir da prática reflexiva docente, integrados na "liberdade, na cidadania e na democracia" (Imbernón, 2009, p. 14). Para o autor, os contextos diferenciados devem ser considerados, rompendo-se com os padrões estabelecidos de linearidade na forma de pensar e agir dos educadores, dando voz a outras "manifestações culturais" e "identidades sociais".

Freire (2019) apresenta, com muita clareza, as dimensões que compõem o profissional docente no contexto do mundo contemporâneo e inicia com uma reflexão sobre os saberes que demandam a prática educativa, pontuando que o ato humano de ensinar "[...] não é transferir conhecimento, mas criar as possibilidades para a sua produção ou a sua construção" (Freire, 2019). Nessa relação, o autor denuncia um ato entre um sujeito e um objeto, um que forma e outro que é formado, descaracteriza a ação dialógica e dialética entre sujeitos ativos que ensinam e aprendem ao mesmo tempo, na construção de um processo histórico, social e cultural.

Nóvoa (1992, p. 25) expressa a importância de propor aos professores uma formação crítico-reflexivaparticipativa, inserir o docente como protagonista do seu próprio percurso formativo para construir uma identidade pessoal e profissional. "A formação não se constrói por acúmulo de cursos, conhecimentos ou técnicas, mas um trabalho de reflexibilidade crítica [...]" sobre as práticas de reconstrução permanente, dando status ao saber da experiência que se complementa com o saber acadêmico.

Contextualizando a realidade de Fortaleza, temos o Plano Municipal de Educação (PME), que é um planejamento estratégico que organiza a política educacional do município e tem por missão assegurar a concretização de diretrizes, metas e objetivos do PNE (Brasil, 2014). Nessa perspectiva, cumpre a diretriz da elaboração e alinhamento dos planos decenais dos estados e municípios, assegurando o compromisso de promover uma escola pública de qualidade. 
Considerando as narrativas expressas pelos sujeitos da pesquisa, a política de formação continuada, precisa considerar o protagonismo docente, ouvir o professor e dar espaço para que o processo formativo ocorra numa dinâmica que possibilite ao docente a participação efetiva em debates e discussões com seus pares e outros atores sociais, compartilhando experiências e saberes profissionais no espaço da unidade escolar, a que chamamos de formação em contexto.

Corroborando com a ideia de protagonismo docente, Imbernón (2011) defende uma formação que atenda às necessidades dos professores, legitimando o percurso formativo e a carreira docente para o desenvolvimento profissional.

Em uma sociedade democrática é fundamental formar o professor na mudança e para a mudança por meio do desenvolvimento de capacidades reflexivas em grupo, e abrir caminho para uma verdadeira autonomia profissional compartilhada, já que a profissão docente precisa partilhar o conhecimento com o contexto (Imbernón, 2011, p. 19).

Proença (2018) defende uma abordagem sobre a formação de professores, “[...] como espaços de criação, de singularidades, de autoria de sujeitos que optam pela docência como projeto de vida". Para a autora, o processo de formação envolve "[...] transformação, ressignificação, reelaboração e refletir sobre a própria ação e recriação, enquanto movimento contínuo de busca e de constituição de uma identidade pessoal e profissional” (Proença, 2018).

Coll (apud Proença, 2018) coloca que "[...] o processo formativo envolve fatos, ações, opiniões, crenças e conhecimentos que, em maior ou menor intensidade acabam se associando à profissão". Ser professor não é apenas uma profissão, mas reflete uma escolha que envolve as experiências e a história de vida das pessoas, tem um caráter subjetivo, como um "articulador de significados", segundo expressa Morin (2002). A formação busca dar sentido aos saberes e fazeres pedagógicos, numa ação autônoma, responsável e comprometida com a aprendizagem do aluno.

$\mathrm{Na}$ tentativa de explicitar o pensamento dos autores, podemos dizer que a formação docente potencializou o professor a se conhecer enquanto sujeito protagonista, que ensina, aprende e reflete sobre sua prática, dando uma nova oportunidade ao fazer pedagógico, que se constitui, a partir de suas histórias e experiências da vida social e profissional.

\section{Considerações Finais}

O contexto social e histórico do século XXI assiste a uma verdadeira revolução estrutural na sociedade. O conhecimento passa a ser o bem mais precioso após a vida, as famílias assumem formatos diversos, os meios de comunicação e as tecnologias são os principais vetores de transformação, adquirem força e poder de interferir diretamente nas formas de pensar, ser e agir das pessoas no mundo.

A prática educativa segue outros rumos e trajetórias, mediatizados pela cultura informativa e tecnológica. A instituição escolar é desafiada a assumir novas funções e adotar procedimentos que condigam com o novo contexto socioeconômico, político, histórico e cultural, fato que impõe à profissão docente competências, saberes e experiências para potencializar a ação pedagógica.

O contexto atual exige uma mudança radical na forma de conceber, organizar e concretizar o funcionamento da escola. A sociedade contemporânea é fluida e está em constante processo de mudança. Vivemos em um novo século, monitorado e conduzido pela força das comunicações, das tecnologias e do conhecimento, que dominam o cenário nacional e internacional. A proposta pedagógica da escola precisa, constantemente, ser analisada, avaliada e adaptada para responder às novas demandas e exigências impostas pelas transformações do século XXI.

Diante desse novo contexto, a política educacional vem imprimindo à educação pública um novo olhar para um novo fazer. Com a publicação da BNCC (2017), foi possível estabelecer uma trajetória mais consistente e coerente com a realidade do século XXI. A etapa da educação infantil considerou a essência do seu currículo, segundo as Diretrizes Curriculares Nacionais da Educação Infantil (DCNEI/2009) e apresentou um arranjo curricular, de forma integrada e 
contextualizada, em “campos de experiências", articulando com os objetivos de aprendizagem - artigo $9^{\circ}$ da Resolução n. 05 , de 2009 (Brasil, 2009c) - para garantir às crianças de 0 a 5 anos os direitos de aprendizagem (participar, conviver, brincar, expressar, explorar e conhece-se) em função da formação integral e integrada do aluno.

O programa de formação continuada de professor objetivou aprimorar e qualificar o trabalho pedagógico realizado pela rede pública municipal de ensino, adotando a abordagem de uma escola dialógica, inclusiva, protagonista e reflexiva, com professores e gestores competentes e comprometidos em realizar na íntegra a função social da escola. A educação, como compromisso político, deve estabelecer a formação de um novo ser humano para uma nova sociedade, marcada pela força do conhecimento, da comunicação e da tecnologia.

Os sujeitos da pesquisa expressaram que a formação promoveu momentos ricos de troca de experiências, ideias, conceitos e concepções com outros professores, permitindo comparar, avaliar e executar uma ação pedagógica mais consciente e intencionalmente política, conforme relata a Professora 9: “[... A mudança de vários paradigmas, desde a visão sobre a infância até a documentação pedagógica, a qual eu não tinha a dimensão da importância de documentar de forma consciente e protagonista".

Os sujeitos pesquisados enfatizaram em suas narrativas, que a formação continuada deveria apresentar uma continuidade dos temas abordados e aprofundar mais os estudos para uma melhor compreensão e reflexão sobre o fazer pedagógico, como premissa básica para o desenvolvimento integral da criança. A formação poderia realizar momentos de auto avaliação para que os professores pudessem, de forma autônoma, ressignificar suas práticas pedagógicas, “[...] percebendo que teoria e prática se sustentam mutuamente" (Professora 10).

Acerca do questionamento sobre a formação continuada ter impactado de forma positiva na prática pedagógica do professor, a maioria concordou com a afirmativa, mas pontuaram sobre a importância de os professores estarem abertos às mudanças, associando compromisso, dedicação e interesse, os quais reverberam suas concepções acerca do trabalho pedagógico que realizaram, considerando os documentos oficiais que compõem o acervo teórico da política da educação básica.

As temáticas das formações apareceram como algo que deve ser significativo para possibilitar ao docente reflexão e aprimoramento da sua prática, realizar trocas de experiências entre seus pares, favorecer o protagonismo dos alunos, dinamizar os conhecimentos com novas estratégias, visando superar os desafios e a complexidade da rotina da sala de aula.

Os sujeitos da pesquisa indicaram que as principais deficiências se relacionam com as rupturas do programa de formação, que não seguiu uma linha de continuidade quanto às temáticas apresentadas nos cursos de formação continuada. As narrativas evidenciaram que os objetivos do programa de formação de 2017 foram plenamente realizados. As escolas, centro de educação infantil e creches parceiras conseguiram reelaborar ou revisitar suas propostas pedagógicas, mobilizando, envolvendo e realizando momentos de estudos com os profissionais da educação para discutirem e decidirem sobre as estratégias de gestão e trajetórias pedagógicas, para dar fluidez ao processo de aprendizagem e desenvolvimento integral dos alunos.

Os relatos da pesquisa indicaram que os sujeitos têm identificação afetiva com a profissão que escolheram, a insatisfação se deve à falta de reconhecimento e valorização dos profissionais de educação via poder público e sociedade civil. As políticas públicas de educação precisam ser efetivamente concretas e exequíveis, considerando as demandas expressas pela categoria docente.

O Programa de Formação Continuada da rede pública municipal de Fortaleza constituiu uma ferramenta básica para aprimorar o trabalho pedagógico dos profissionais de educação e oportunizar, em médio e longo prazos, a redução das desigualdades sociais, função básica da política educacional brasileira. 
A pesquisa possibilitou conhecer as perspectivas, os dilemas e percursos expressos pelos profissionais da educação infantil, contribuindo para uma política permanente de valorização profissional que objetiva a qualificação do ensino público como principal desafio da sociedade brasileira no século XXI.

Sugiro para os trabalhos futuros, possam aprofundar a temática da Política de Formação Continuada de Professores da Rede Pública Municipal de Fortaleza, na perspectiva de realizar uma análise sobre os desafios educacionais contemporâneos no município de Fortaleza, a construção da identidade profissional docente, a articulação entre teoria e prática a partir do currículo estabelecido e vivido e as relações de impacto entre a formação continuada e desempenho escolar dos alunos.

\section{Agradecimentos}

A Secretaria Municipal de Educação de Fortaleza; aos gestores; aos coordenadores pedagógicos; aos professores das unidades escolares do distrito III e aos técnicos formadores que me oportunizaram realizar a pesquisa.

\section{Referências}

Brasil. (1988). Constituição da República Federativa do Brasil de 1988. Brasília. http://www.planalto.gov.br/ccivil_03/constituicao/constituicao.htm.

Brasil. (1996). Ministério da Educação. Lei n. ${ }^{\circ}$ 9.394, de 20 de dezembro de 1996. Estabelece as diretrizes e bases da educação nacional. Brasília. http://www.planalto.gov.br/ccivil_03/leis/19394.htm.

Brasil. (2009a). Ministério da Educação. Lei n. ${ }^{\circ}$ 12.056, de 13 de outubro de 2009. Acrescenta parágrafos ao art. 62 da Lei n..$^{\circ} 9.394$, de 20 de dezembro de 1996. Brasília. http://www.planalto.gov.br/ccivil_03/_ato2007-2010/2009/lei/112056.htm.

Brasil. (2009b). Ministério da Educação. Diretrizes Curriculares Nacionais para a Educação Infantil. Brasília. http://portal.mec.gov.br/dmdocuments/diretrizescurriculares_2012.pdf.

Brasil. (2013). Ministério da Educação. Lei n. ${ }^{\circ}$ 12.796, de 4 de abril de 2013. Altera a Lei $\mathrm{n}^{\circ}$ 9.394, de 20 de dezembro de 1996. Brasília. http://www.planalto.gov.br/ccivil_03/_ato2011-2014/2013/lei/112796.htm.

Brasil. (2014). Ministério da Educação. Lei n.o 13.005, de 25 de junho de 2014. Aprova o Plano Nacional de Educação - PNE e dá outras providências. Brasília. https://pesquisa.in.gov.br/imprensa/jsp/visualiza/index.jsp.

Brasil. (2016). Ministério da Educação. Decreto n. ${ }^{\circ}$ 8.752, de 9 de maio de 2016. Dispõe sobre a Política Nacional de Formação dos Profissionais da Educação Básica. Brasília. http://www.planalto.gov.br/ccivil_03/_ato2015-2018/2016/decreto/d8752.htm.

Brasil. (2017). Ministério da Educação. Base Nacional Comum Curricular: educação é a base. Brasília. http://portal.mec.gov.br/index.php?option=com_docman\&view=download\&alias=79611.

Brasil. (2019). Ministério da Educação. Resolução CNE/CP n. ${ }^{\circ}$ 2, de 20 de dezembro de 2019. Define as Diretrizes Curriculares Nacionais para a Formação Inicial de Professores para a Educação Básica e institui a Base Nacional Comum para a Formação Inicial de Professores da Educação Básica (BNCFormação). Brasília. http://portal.mec.gov.br/index.php?option=com_docman\&view=download\&alias=135951-rcp002-19\&category_slug=dezembro-2019pdf\&Itemid=30192.

Ceará. (2019). Secretaria da Educação do Estado do Ceará. Documento Curricular Referencial do Ceará: educação infantil e ensino fundamental. Fortaleza. https://www.seduc.ce.gov.br/wp-content/uploads/sites/37/2020/02/DCRC_2019_OFICIAL.pdf.

Fortaleza. (2015). Secretaria Municipal da Educação. Lei n. ${ }^{\circ} 10.371$ de 24 de junho de 2015. Aprova o Plano Municipal de Educação 2015-2025, alinhado ao Plano Nacional de Educação, Lei no 13.005, de 25 de junho de 2014, e revoga a Lei no 9 441, de 30 de dezembro de 2008, do Poder Executivo Municipal. Fortaleza. http://intranet.sme.fortaleza.ce.gov.br/files/2018/PME_2015_2025.pdf.

Fortaleza. (2016). Secretaria Municipal da Educação. Proposta curricular para a Educação Infantil da Rede Municipal de Ensino de Fortaleza. Fortaleza:SME. http://educacao.fortaleza.ce.gov.br/index.php/publicacoes/category/1-educacao-infantil?download=2:proposta-curricular-da-educacao-infantil.

Fortaleza. (2017). Secretaria Municipal da Educação. Coordenadoria de Educação Infantil. Programa de Formação Continuada da Rede Municipal de Fortaleza. Fortaleza: SME.

Fortaleza. (2018). Secretaria Municipal da Educação. Coordenadoria de Educação Infantil. Programa de Formação Continuada da Rede Municipal de Fortaleza. Fortaleza: SME.

Fortaleza. (2020). Decreto n. ${ }^{\circ} 14.611$, de 17 de março de 2020. Decreta situação de Emergência em Saúde e Dispõe sobre Medidas para Enfrentamento e Contenção da Infecção Humana pelo Novo Coronavírus. Fortaleza: Prefeitura Municipal de Fortaleza. https://diariooficial.fortaleza.ce.gov.br/download-

Freire, P. (2019). Pedagogia da autonomia: saberes necessários à prática educativa. 58ed. Ed. Paz e Terra. 
Research, Society and Development, v. 11, n. 3, e12311322361, 2022

(CC BY 4.0) | ISSN 2525-3409 | DOI: http://dx.doi.org/10.33448/rsd-v11i3.22361

Imbernon. F. (2009). Formação permanente do professorado: novas tendências. Ed. Cortez.

Imbernón. F. (2011). Formação docente e profissional: formar-se para a mudança e a incerteza. 9. ed. Cortez.

Morin. E. (2002). Os sete saberes necessários à educação do futuro. Ed. Cortez.

Nóvoa. (1992). A. Formação de professores e profissão docente. In: NÓVOA, A. (org.). Os professores e sua formação. Lisboa: Ed. Dom Quixote.

Proença. M. (2018). A. Prática docente: a abordagem de Reggio Emília e o trabalho com projetos, portfólios e redes formativas. Ed. Panda Educação. 